\title{
Using instructional design principles in developing skill acquisition workshops in hand surgery-our experience
}

\begin{abstract}
Hand surgery is very much a psychomotor dominant specialty requiring the need for predictable, reliable and cost effective means of transferring and developing surgical skills. The need for a high quality simulations model to acquire skills is important in skill training. In this paper we identified real world problems of skill gaps in hand surgery and used the theories of instructional design (ID) to analyse the instructional needs in the problems and then generated solutions using the principles of ID. Based on the individual needs of the learners and entry behavior and characteristics, the framework developed instructional activities and materials and used the concept of the flipped classroom, allowing for effective and efficient transfer of information and skills allowing for adequate feedback and assessment to achieve the stated objectives of the instructions. It included generation of appropriate tools to evaluate the effectiveness of the whole ID framework.
\end{abstract}

Trainees may be trusted to perform a professional task with sufficient independence. This professional activity that is required in the community is called a Entrustable Professional Activities (EPAs). EPAs are entrusted when a supervisor is confident the trainee can demonstrate the knowledge, skills and attitude required of the task, knows when to ask for additional help and can be trusted to seek assistance in a timely manner. The authors developed the EPA for trainees in hand surgery care based on prior unpublished research. 4 skill acquisition workshops were conceptualized and developed based on the ADDIE (Analyse, Design, Develop, Implement, and Evaluate) framework of Instructional Design.

The 4 workshops were: Injured Hand Assessment; Flexor Tendon Workshop; Hand Fracture Fixation; Micro-neural repair workshop. The ADDIE and Gagnes 9 events of instruction framework was used to analyse the instructional goals and needs and formulated strategies to bridge the gap by developing the instructional events for delivery of the learning in the form of an intensive course to transfer knowledge and skills using a high fidelity simulated models. Using Gagnes 9 events of instruction, the curriculum, pedagogy, and assessment were developed and the resource materials were posted on an open online learning management system. (www.handsurgeryedu.com). This formed the basis of the flipped workshop to maximizing resources during the face to face skill acquisition workshops.

This paper shows that the use of the Instructional Design models like ADDIE and Gagne's nine events and the use of open educational resources hosted on an open learning management system is a useful strategy in designing surgical skill workshops and is a reliable and predictable tool in producing learning programs for surgeons in a cost effective manner.

Keywords: entrustable professional activities, instructional design, addie, flipped workshop, open online educational resources, OER
Volume 3 Issue I - 2015

\author{
Vaikunthan Rajaratnam, Tong Pei-Yein \\ KTPH Alexandra Healthcare, Singapore
}

Correspondence: Vaikunthan Rajaratnam, Consultant Hand Surgeon, KTPH Alexandra Healthcare, 60 Jalan Mata Ayer 02-07, Singapore, Tel (65)660247I8, Email vaikunthan@gmail.com

Received: June 29, 2015 | Published: August 04, 2015
Abbreviations: Epas, entrustable professional activities; ADDIE, analyse, design, develop, implement, and evaluate; EPA, entrustable professional activities; OER, open educational digital resource; MOODLE, materials were created and distributed on an open online learning management system; SCORM, sharable content object reference model

\section{Introduction}

Hand Surgery is a specialist in surgery that focuses in the care of patients with ailment and injuries of the hand. It roots are based in plastic and orthopaedic surgery. ${ }^{1,2}$ In the community injuries of the hand and wrist produce significant economic impact. De Putter CE et al. $^{3}$ in their research found that in the Netherlands hand and wrist injuries ranked number one in the order of most expensive injury types and cost to the economy was US\$740 million. 56\% of these cost were attributed to indirect productivity cost. Within the overall group of hand and wrist fractures hand and finger fractures of the most expensive group and were largely due to the high productivity cost in the related age group of 20 to 64 years. ${ }^{3}$ The prevalence of hand injuries and ailments in the community is significant. For optimal outcome for management of these conditions, the doctors caring for these patients require adequate post graduate knowledge and skills. ${ }^{4}$ There is a need in the community for doctors who have the competency to be able to holistically manage a patient with ailments of the hand.

In this paper the author explores the use of an instructional design model to design and develop targeted skill acquisition program that is community orientated for hand surgeons and then deliver it through hybrid model using an on line learning management system and high fidelity simulation workshops to improve the efficacy of the learning. 


\section{Literature review}

The aim of any post graduate medical training program is the production of a doctor who is able to manage competently the commonly seen and serious conditions of the speciality in the community independently. ${ }^{2}$ The use of competency based curriculum has been widely established in the literature. ${ }^{5-7}$ However for a competency-based curriculum, to have face and content validity, it has to be relevant in the context of the workplace. ${ }^{8}$ This ensures that the product of the training will be fit for purpose in the community for this speciality by all stake holders. ${ }^{9}$ It must have clearly stated outcomebased terms that allow assessment of students' progress in developing the competencies of the profession and the public expect of a doctor. ${ }^{10}$ The foundations of the competency-based medical education is a focus on outcomes and emphasis on abilities, de-emphasis on time-based training and the promotion of learner centredness. This allowed for the focus of outcomes as the end product of education and is tied to the needs of the community that is served by the doctors and involves the explicit definitions of all the essential domains of competency there are needed to be acquired during the process of postgraduate medical education..$^{10}$ To be able to develop a robust and meaningful competency-based curriculum an educational need must be performed..$^{10}$ This can be in the form of practice profiling, task analyses, community-based needs and the identification of entrustable professional activities (EPA) for the speciality or subspecialty. ${ }^{11}$

The steps include the following

a. Identify the abilities needed of graduates

b. Explicitly define the required competency and their components

c. Define milestones along a development course for the competencies

d. Select educational activities, experiences and instructional methods.

e. Select assessment tools to measure progress along the milestones.

f. Design an outcomes evaluation of the program. ${ }^{10}$

So in developing a curriculum for a program it is important therefore to be able to identify the competency that are required in the speciality for doctors to practice safely and independently in the context of the community. ${ }^{8}$ The fundamental principles of an instructional program is to first identify the needs of both the learner and the community. ${ }^{12}$ And therefore a community orientated curriculum i.e. what are the key portfolio of cases seen in the community - is what a learner needs to know.

The abundance of knowledge within the medical domain makes it impossible for trainee to be knowledgeable in all areas. Workplace curricula is the development of a curriculum that is relevant in the workplace. ${ }^{8}$ Once the required competency to practice in the community has been identified, the various knowledge and skills required to attain that competency will need to then be incorporated in the instructional design to develop that competency. ${ }^{8}$

Instructional design models in developing medical education programs have been recently used. ${ }^{13}$ The ADDIE and the Gagne models have been used successfully in medical education. ${ }^{14-16}$
The ADDIE model is based on a well-defined instructional design system, originally developed by the US military. The original ADDIE system consisted of 5 phases: analysis, design, development, implementation, and evaluation. It is a process of identifying problem areas within a system, targeting them for improvement, and evaluating the effect of any interventions. ${ }^{17}$

Gagne's nine events of instructions first described by Robert Gagne $^{18}$ include

a. Gain attention

b. Inform learners of objectives

c. Stimulate recall of prior learning

d. Present the content

e. Provide "learning guidance"

f. Elicit performance (practice).

g. Provide feedback

h. Assess performance

i. Enhance retention and transfer to the job Its use in medicine has been well documented. ${ }^{14,19}$

\section{Research methodology}

The author (RV) developed the EPA for trainees in hand surgery care based on prior unpublished research. 4 skill acquisition workshop were conceptualized and developed based on the ADDIE (Analyse, Design, Develop, Implement, and Evaluate) and Gagne's nine events of framework of Instructional Design. The 4 workshops were: Injured Hand Assessment; Flexor Tendon Workshop; Hand Fracture Fixation; Micro-neural repair workshop. The ADDIE framework was used to analyse the instructional goals and needs. Strategies were formulated to bridge the gap by developing the instructional events for delivery of the learning in the form of open on line asynchronous course to transfer knowledge and skills based on a flipped workshop concept. ${ }^{20}$ This was blended with using a high fidelity simulated animal models ${ }^{21}$ for psychomotor skill acquisition. Using Gagne's 9 events of instruction, the curriculum, pedagogy, and assessment were developed and open educational digital resource (OER) materials were created and distributed on an open online learning management system (MOODLE) (www.handsurgeryedu.com). This included instructional videos, PowerPoint presentations, text based resources and on line assessment of and for learning and Sharable Content Object Reference Model (SCORM) compliant e learning objects covering the knowledge and skill domains required for the specific task in the specific modules. This formed the basis of the flipped and blended workshop to maximizing resources during the face to face skill acquisition workshops. All participants were informed 2 weeks prior to the workshop to register and study the materials online (www.handsurgeryedu.com) and warned that no didactic lecture will be delivered during the workshop. They were assessed on the knowledge acquired from the OER by an assessment performed on the day of the face to face workshop using a smart online live student response system (www.socrative.com). Over a period of 3 years (2011 to 2014) these instructions were delivered as blended programs as part of the orthopaedic surgery residency training in Singapore. Their effectiveness and usefulness were evaluated using online questionnaires. The questionnaire was of a convergent design 
,included a fixed-response (quantitative) component with questions meant to evaluate specific aspects and contents of the workshop, as well as an open-ended (qualitative) component aimed at exploring participant perspectives. This was then deployed as a Google form on the author's (RV) Google drive and the link generated was emailed to all participants for their response.

\section{Results}

The OER that were produced were collated and uploaded. They included video presentation of PowerPoint lectures and PDF resource materials relevant to the topics. On line interactions and engagement were promoted by using e learning objects on the subject matter created using Articulate Storyline and deployed on the portal. This allowed for self-assessment of higher order learning by the participants as it allowed for problem based and scenario based learning. ${ }^{22}$

\section{Data analysis}

The online survey data was exported from the Google Drive and analysed using Excel 2013. Mean, distribution and confidence intervals with $95 \%$ confidence intervals for the data were calculated using the functions within Excel. Charts and histograms were generated using Google forms inbuilt functionalities of response summary. Over the period of time 117 participants have gone through the various program and $57(49 \%)$ had responded to the online questionnaire. Likert scores were ranged 1 (very poor) to 5(very good). For the Likert items evaluating the various questions posed in the survey the data is summarised in the table below with a confidence interval of $95 \%$ (Table 1).

Table I Likert scores

\begin{tabular}{|c|c|c|c|c|}
\hline Question & Mean & $\begin{array}{l}\text { Standard } \\
\text { deviation }\end{array}$ & $\begin{array}{l}\text { Lower } \\
\text { limit }\end{array}$ & $\begin{array}{l}\text { Upper } \\
\text { limit }\end{array}$ \\
\hline Overall Impression & 4.6 & 0.5 & 4.4 & 4.7 \\
\hline $\begin{array}{l}\text { Content usefulness and } \\
\text { Interest }\end{array}$ & 4.6 & 0.5 & 4.4 & 4.7 \\
\hline $\begin{array}{l}\text { Focus of workshop up to } \\
\text { expectations }\end{array}$ & 4.7 & 0.5 & 4.6 & 4.8 \\
\hline $\begin{array}{l}\text { Content was adequate in } \\
\text { terms of the coverage of the } \\
\text { subject }\end{array}$ & 4.5 & 0.6 & 4.4 & 4.7 \\
\hline $\begin{array}{l}\text { Were they readable and } \\
\text { helpful }\end{array}$ & 4.5 & 0.6 & 4.3 & 4.6 \\
\hline Vocabulary was understandable & e4.5 & 0.6 & 4.4 & 4.7 \\
\hline Use of class time was good & 4.5 & 0.6 & 4.4 & 4.7 \\
\hline
\end{tabular}

\section{Some of the free comments on the contents produced}

Great presentation from the various speakers who have shared their experiences through this workshop. More focus could have been given to the difficulties/sequelae of repairing zone II flexor injuries.

\section{Overall free comments}

I enjoyed this workshop and the discussion on hand injuries after that. Thanks Dr.

A good course, adequate opportunities for practice

Was very helpful thanks :)

Great course! Could not find any fault with it!

Very interesting course

The case discussion by $\mathrm{Mr}$.... was very interesting. Especially the war time injuries.

Interesting and useful workshop.

Sufficiently long. Thank you for your time.

Would be even better with more faculty to student ratio for practical (like flexor workshop) but was still a very

good course still.

Better quality of instruments and more supply of suture material.

Very good practical lesson. Learnt a lot.

Have learnt a lot from the different speakers through their sharing. Would like to have this learning opportunity

in future.

More suture support.

Free information, good instructional course for residents.

\section{Discussion \& Conclusion}

E-learning with mobile and wireless technologies is evolving and transforming education and introduces new learning environment and requires new interactive and dynamic content to be produced. ${ }^{23}$ Using the ADDIE and Gagne's nine events of instruction it is possible to create templates and framework for others to use to design learning programs in medical education. ${ }^{19}$ These allow for effective utilisation of face to face times in a blended learning program..$^{24}$ The use of these OER allows for on demand, self-paced and self-directed learning ensuring effective learning to occur. ${ }^{25,26}$ This study has shown that it is possible to create open educational resources in hand surgery using instructional design framework and that these can be used to design and conduct flipped workshop in hand surgery skill acquisition. This study, demonstrates that learners were satisfied with a flipped workshop approach to surgical skill training in hand surgery and the flipped workshop were rated positively in keeping with similar research findings in other areas. ${ }^{24}$ It has also showed satisfaction among the learners of the content quality of the OER, focus of the workshops and use of class time.

\section{Implications for future research}

Further research needs to address the effect of this learning strategy in producing changes in practice. A use of Kirkpatrick Learning Evaluation Model can be used to assess the full and meaningful level of learning of the new skills. Recommendations for further research would be in the area of comparing similar instructions program using conventional methods and the flipped approach. There is scope to expand on this study to include a more open-ended, qualitative study 
of learner perceptions of the effectiveness of the concept of OER and flipped workshops.

\section{Acknowledgments}

None.

\section{Conflicts of interest}

The authors declare there is no conflict of interest.

\section{References}

I. Lees V. The Postgraduate diploma in hand surgery: training hand surgeons of the future in the UK.J Hand Surg Eur. 2008;33(2):98-102.

2. Postgraduate education and training.

3. De Putter CE, Selles RW, Polinder S, et al. Economic impact of hand and wrist injuries: health-care costs and productivity costs in a populationbased study.J Bone Joint Surg Am. 2012;94(9):e56.

4. Wilcock P, Janes G, Chambers A. Health care improvement and continuing interprofessional education: continuing interprofessional development to improve patient outcomes. J Contin Educ Health Prof. 2009;29(2):84-90.

5. Brightwell A, Grant J. Competency-based training: who benefits? Postgrad Med J postgradmedj-2012-I3088I. 2012.

6. Frank JR, Danoff D. The CanMEDS initiative: implementing an outcomes-based framework of physician competencies. Med Teach. 2007;29(7):642-647.

7. Frank JR, Snell LS, Cate OT, et al. Competency-based medical education: theory to practice. Med Teach. 2010;32(8):638-645.

8. Mulder H, Cate OT, Daalder R, et al. Building a competency-based workplace curriculum around entrustable professional activities: The case of physician assistant training. Med Teach. 20 10;32( I0):e453-e459.

9. Bleakley A, Brennan N. Does undergraduate curriculum design make a difference to readiness to practice as a junior doctor? Med Teach. $2011 ; 33(6): 459-467$.

10. Holmboe ES, Sherbino J, Long DM, et al. The role of assessment in competency-based medical education. Med Teach. 20I 0;32(8):676-682.

II. Ten Cate O. Entrustability of professional activities and competencybased training. Med Educ. 2005;39: I I76-II77.

12. Woo K, Rowe VL, Weaver FA, et al. The results of a needs assessment to guide a vascular surgery skills simulation curriculum. Ann Vasc Surg. 2012;26:198-204.

13. Delf P. Designing effective eLearning for healthcare professionals. Radiography. 2013;19(4):315-320.

14. Khadjooi K, Rostami K, Ishaq S. How to use Gagne's model of instructional design in teaching psychomotor skills. Gastroenterol Hepatol Bed Bench. 201 I;4(3): I 16-119.

15. Lai CY, Liou WC. Rapid ADDIE Curriculums Design Model Based on the Heterogeneous Multimedia Information Integration. IEEE; 2007:485-490.

16. Siribaddana P.The future of instructional designing in medical education: letting the computer do the work. Sri Lanka J Bio-Med. 2009; I(I):76-85.

17. Houghland JE, Druck J. Effective clinical teaching by residents in emergency medicine. Ann Emerg Med. 20 10;55(5):434-439.

18. Gagne RM, Wager WW, Golas K, et al. Principles of instructional design. 5th ed. Belmont, USA: Cengage Learning; 2004:664.

19. $\mathrm{Ng}$ JY. Combining Peyton's four-step approach and Gagne's instructional model in teaching slit-lamp examination. Perspect Med Educ. 20|4;3(6):480-485.

20. Leung JYC, Kumta SM, Jin Y, et al. Short review of the flipped classroom approach. Med Educ. 20 I4;48: I I 27.

21. Tan S, Power D, Rajaratnam V. Animal models for training in tendon surgery: sheep's forelimbs.J Hand Surg Eur. 2010;35(2):I 52-I53.

22. Bonnetain E, Boucheix JM, Hamet M, et al. Benefits of computer screenbased simulation in learning cardiac arrest procedures. Med Educ. 2010;44(7):716-722.

23. Pereira ORE, Rodrigues JJPC. Survey and analysis of current mobile learning applications and technologies. ACM Comput Surv. 2013;46(2): I35.

24. Moffett J, Mill AC. Evaluation of the flipped classroom approach in a veterinary professional skills course. Adv Med Educ. 20I4;Pract 5:4I5425.

25. Denton DW. Enhancing instruction through constructivism, cooperative learning, and cloud computing. Tech Trends. 20I2;56(4):34-4I.

26. Grant P, Basye D. Personalized learning. Iste, Washington DC, USA, 2014:1-189. 